\title{
OS HORIZONTES DE EXPECTATIVAS DE PROGRESSO: A ORGANIZAÇÃO DA INSTRUÇÃO PROFISSIONAL NOS DISCURSOS DO SENADO MINEIRO*
}

\author{
Bárbara Braga Penido Lima** \\ lattes.cnpq.br/3703736805740650
}

\begin{abstract}
Resumo: Este trabalho visa analisar os horizontes de expectativas contidos nos discursos do Senado Mineiro, entre 1891 e 1906, pesquisados nos Anais do Senado Mineiro. A partir da documentação reunida, buscamos interpretar como as ideias de progresso e instrução profissional norteavam as concepções dos senadores. Procuramos compreender de que modo as instituições escolares de formação profissional foram entendidas pela elite política como instrumento para atingir o desenvolvimento econômico e social; isto é, usando do vocabulário discursivo da época, o engrandecimento mineiro. Desse modo, tomamos como aportes teórico-metodológicos os conceitos de espaço de experiência e horizonte de expectativas cunhados por Reinhart Koselleck; o conceito de repertório conforme a definição de Angela Alonso e as proposições de análise do discurso realizadas por Patrick Charaudeau. Ao considerar o Senado Mineiro como espaço de embates retóricos, pretendemos compreender como o vocábulo progresso foi mobilizado para discutir a instalação de instituições de formação profissional como estratégia para equipara o estado mineiro aos núcleos sociais entendidos como modernos e civilizados.
\end{abstract}

Palavras-chave: Progresso; Senado Mineiro; Instrução Pública; Instrução Profissional.

\section{PROGRESS' HORIZONS OF EXPECTATIONS: THE FRAMING OF PROFESSIONAL EDICATION IN DISCOURSES FROM THE SENATE OF MINAS GERAIS}

\footnotetext{
* Este texto é um dos resultados da pesquisa de mestrado de Bárbara B. P. Lima, intitulada "Affonso Penna e os repertórios do engrandecimento mineiro (1874-1906)", realizada no Programa de Pós-Graduação em Educação Tecnológica do Centro Federal de Educação Tecnológica de Minas Gerais, sob orientação do Prof. Dr. Irlen Antônio Gonçalves e co-orientação do Prof. Dr. James William Goodwin Jr..

*** Mestre em Educação Tecnológica pelo Centro Federal de Educação Tecnológica de Minas Gerais (Brasil). Contato: bragapenido@gmail.com.
} 
Abstract: This paper aims to analyse the horizons of expectations which lay within Minas Gerais State between the years of 1891 and 1906, available at Minas Gerais Senate Records. From the gathered documents, we aimed to provide an interpretation of how the notions of progress and professional education outlined the senators ideas. We intended to comprehend in which ways professional education institutions were understood by some of the most powerful politicians as an instrument to achieve social and economical development; which was the enlargement of Minas Gerais state, as senators would address to it at that time. Therefore, we have chosen the following theoretical-methodological contributions: Reinhart Koselleck's concepts of space of experience and horizons of expectations; Angela Alfonso' concept of repertoire according to the definition; and Patrick Charaudeau's propositions into speech analysis. We considered Minas Gerais Senate as a field of rhetoric attacks in order to understand how the word progress was brought up in arguments considering the establishment of professional education institutes as a strategy to equate Minas Gerais State to the social areas considered modern and civilised.

Keywords: Progress; Minas Gerais Senate; Public Education; Professional Education.

\section{Introdução}

Os Anais do Senado Mineiro, pesquisados entre 1891 e 1906, ao conter os discursos dos senadores sobre a organização da instrução pública e profissional em Minas Gerais, permitiram verificar as expectativas de progresso dos políticos mineiros para o estado. A partir da documentação reunida, buscamos interpretar como as ideias de progresso ${ }^{1}$ e instrução profissional norteavam as concepções dos senadores. Procuramos compreender de que modo as instituições escolares de formação profissional foram

\footnotetext{
${ }^{1} \mathrm{O}$ termo progresso surge como uma ideia na argumentação dos políticos mineiros, usada em seus embates, debates e disputas no plano discursivo. Assim como Pedro Geraldo Pádua (2012), para justificar a utilização do vocábulo ideia como sinônimo de conceito, recorro à definição estabelecida pelos autores Hilton Japiassú e Danilo Marcondes (1996) e por Nicola Abbagnano (2015), para ambos os termos. Nesse sentido, ao tomar Reinhart Koselleck (2006) como referência, entendemos que os conceitos, ou ideias, foram compreendidos conforme uma dada realidade social e histórica, dentro de um conjunto de experiências compartilhadas; ou seja, percebidos do ponto de vista social e político, dentro de uma conjuntura histórica e social específica.
} 
entendidas pela elite ${ }^{2}$ política como instrumento para atingir o desenvolvimento econômico e social; isto é, usando do vocabulário discursivo da época, o engrandecimento mineiro.

Por meio dessa documentação, tomada como fonte, observamos os espaços de experiência que cunharam o horizonte de expectativas dos políticos mineiros, conforme a proposição de Reinhart Koselleck (2006). Para o autor, por espaço de experiência entendem-se as vivências dos senadores no Congresso Mineiro, onde produziram seus discursos, os quais descortinavam seus anseios, suas angústias, suas esperanças e seus desejos. É o lugar de produção dos repertórios mobilizados na relação entre o passado e o futuro, vivenciado pelos senadores. A definição de horizonte de expectativas servirá de instrumento para compreender as expectativas expressas nos seus discursos referentes aos projetos de instrução pública e instrução profissional no Estado.

Os discursos, percebidos como narrativa construída segundo condições históricas e sociais específicas, constituem uma representação do imaginário social de um grupo de interlocutores, ao qual seu autor pertence, permeados por relações de poderes. Para isso, a metodologia usada é a da análise do discurso, sobretudo a de Patrick Charaudeau (2013). Segundo o autor, os discursos políticos se inscrevem em uma prática social, mobilizados num espaço público, permeados pelas relações de poder nele circunscritos. Heterogêneo, pertencente a diferentes grupos, o discurso é fragmentado em diversos espaços de discussão, de persuasão, de decisão, que ora se recortam, ora se confundem, ora se opõem. John Greville Pocock afirma que analisar o discurso político implica estudar fatos históricos; uma vez que "faz parte desse enfoque pensar os discursos como ações

\footnotetext{
2 O conceito de elites, formulado por José Murilo de Carvalho (2013, p. 17) refere-se aos grupos especiais de elite, marcados por características que os distinguem tanto das massas como de outros grupos de elites, de acordo com o critério de posição. Sob perspectiva semelhante, Claudia Viscardi (2012) definiu as elites políticas mineiras segundo os indivíduos que ocupavam cargos no Executivo e no Legislativo estadual e federal na Primeira República. Para Otavio Dulci (1999, p.107), "a elite política e a elite agrária remontam a uma estrutura socioeconômica tradicional, em que predominavam as atividades rurais". Neste trabalho, o conceito de elite será utilizado para designar os ocupantes dos cargos na administração pública no cenário mineiro e nacional.
} 
para reagir a fatos passados, modificar fatos presentes ou criar futuros" (POCOCK, 2013, p.09).

Entender estes discursos significa considerar como as ideias de progresso, modernidade e instrução pública e profissional, percebidas em seu lugar social como capacidades culturais, foram apropriadas e reapropriadas, organizadas segundo os projetos que visavam o desenvolvimento econômico e social do Estado. As ideias são parte do todo social e se constituem juntamente com ele. Elas se engendram no interior do processo histórico e são constitutivas dele (CAPELATO, 1989, p. 17). Avaliar os discursos dos senadores significa compreender a cena política circunscrita à política mineira; sendo o Senado Mineiro considerado como lugar de produção da instrução e formação profissional, onde se promovia a normatização da escolarização, cujo objetivo seria tornar a criança, o jovem e o adulto trabalhadores cidadãos (GONÇALVES, 2012, p. 17).

Ao situá-los na estrutura de relações de poder da sociedade à qual pertencem, percebemos a apropriação, reprodução e produção de repertórios discursivos, ligados aos modos de pensar e agir e em íntima conexão com a conjuntura histórica, social e cultural de seu lugar de origem. Por repertório entende-se o conjunto de recursos intelectuais disponível numa dada sociedade, imbricados em suas relações históricas e sociais. Composto por criações culturais apreendidas, referem-se aos recursos intelectuais apropriados e compartilhados, segundo um processo deliberado de escolha, conforme a necessidade de compreender certas situações e definir linhas de atuação (SWINDLER, 1986; TILLY, 1993).

O termo indica o conjunto dos recursos teórico-metodológicos, produzidos pelos intelectuais, disponíveis em uma sociedade, numa delimitada conjuntura histórica, que podem ser selecionados e articulados para o jogo político. Imbricados nas práticas sociais e culturais, nas relações da cena política, compõem um conjunto limitado de esquemas que são apreendidos, compartilhados e postos em prática, por meio de um processo seletivo, para compreender certas situações e definir linhas de ação (ALONSO, 2002, p. 39).

O repertório compreende padrões analíticos, noções, argumentos; conceitos; teorias; esquemas explicativos; formas estilísticas; figuras de 
linguagem; metáforas (SWINDLER, 1986); não importando a consistência teórica de seus elementos, uma vez que seu arranjo é histórico e prático. Por arranjo prático, percebemos que os repertórios são criações culturais apreendidas, mas não são delimitadas por uma dada teoria ou resultam de uma propaganda política. Os repertórios constituem-se no jogo das relações políticas e sociais, nos embates perpetrados pelos agentes sociais e definem uma série de esquemas apropriados, compartilhados e utilizados, por meio de processos deliberados de escolha (TILLY, 1993).

Os repertórios seriam os instrumentos utilizados pelos senadores mineiros para compreender o cenário ao qual estão inseridos e definir suas práticas políticas, a exemplo das vislumbradas no âmbito do ensino público e profissional. Ao defenderem o engrandecimento mineiro, os políticos do Estado apreenderam, reproduziram e produziram repertórios consonantes com seus ideais de progresso e modernização, formados em seus respectivos lugares sociais. Os repertórios eram selecionados segundo os projetos de modernização, civilização e progresso. Para modernizar o Estado, as elites recorreram aos recursos teóricos e retóricos disponíveis no "repertório político-intelectual de fins do oitocentos conforme suas possibilidades de explicar a conjuntura" mineira e evidenciar linhas de ação para nela intervir (ALONSO, 2002, p. 44).

Importa salientar que, durante a leitura dos discursos, os termos educação e instrução foram interpretados e utilizados de maneiras diferentes pelos políticos mineiros. A análise dos termos "educação" e "instrução", segundo suas perspectivas lexicográficas, evidenciou a diferenciação de seus sentidos no repertório utilizado pelos políticos. Conforme os estudos realizados por Irlen Antônio Gonçalves sobre a formação do trabalhador republicano, "educação" significa "o ato de educar a pessoa nos aspectos relacionados à direção da vontade e da moral, notadamente, com vistas à formação de costumes e culturas próprias de uma dada sociedade, que estabelece regras de costumes, de boas maneiras e de viver". O autor indicou que "instrução", segundo o Diccionario da Lingua Portuguesa, de Antônio de Moraes Silva, de 1891, designa "a ação de instruir; corresponde ao ensino, à educação literária, a tudo que pode instruir, aos conhecimen- 
tos adquiridos, ao saber" (GONÇALVES, 2012, p. 23). Portanto, a educação compreende o ato de criar mais geral, relacionada à transmissão de valores morais, enquanto a instrução, ainda como meio de conduzir a educação, estaria ligada aos aprendizados adquiridos na escola.

\section{O Senado Mineiro: ideias de progresso e modernidade}

A implantação da República e a instalação do sistema federalista permitiram que cada estado articulasse o próprio sistema político, conforme sua realidade social e econômica. Em Minas Gerais foi instalado o Congresso Mineiro, composto por Senado e Câmara dos Deputados, que passou a exercer o poder legislativo estadual. Percebido como ambiente de experiência compartilhada, em que formas de pensar e agir estão relacionadas a práticas e redes sociais, não era formado por um grupo coeso (ALONSO, 2002). Foi uma instituição representativa das oligarquias dominantes da época, cujo objetivo era organizar a administração pública e fomentar o engrandecimento mineiro, através do desenvolvimento econômico e social, tendo em vista as ideias de progresso, de ciência e de civilização.

Os políticos mineiros formaram um grupo intelectualmente heterogêneo, uma vez que, seus discursos, em diversos momentos, sustentaram opiniões divergentes; sendo orientados por interesses regionais, conforme a ideia do mosaico mineiro apresentada por John Wirth (1982). Conforme o autor, as fronteiras geográficas de Minas Gerais constituíram um mosaico de sete zonas ou regiões divergentes; sendo que, para além da diferenciação geográfica e, por vezes, a partir dela, tais zonas se distinguiram segundo características econômicas, políticas e culturais. O desenvolvimento econômico dessas zonas, desarticulado e descontínuo, ocorrido em processos temporais diferentes, incidiria diretamente na organização da política mineira. Era um "arquipélago de regiões distintas e isoladas entre si, uma miscelânea de partes esgarçadas, mergulhadas em historicidades fundamentalmente divergentes" (GOODWIN JR., 2015, p. 17-18). 
Embora representantes de suas zonas eleitorais, os políticos mineiros foram analisados como integrantes do mesmo lugar social, o Congresso Mineiro, entendido como local de constituição de uma rede de contatos, permeado por relações afetivas (de aproximação e/ou rejeição), por meio da convivência entre pares (GOMES, 2004, p. 53). A rede organizacional estabelece um circuito de sociabilidade que, ao mesmo tempo, situa o sujeito num mundo cultural e lhe permite interpretar o mundo político e social de seu tempo. Segundo Pedro Pádua (2012, p. 25), os políticos mineiros compartilhavam um vocabulário comum, estavam sujeitos a regras comuns, sendo assim agrupados numa mesma tradição cultural ou cultura política ${ }^{3}$, o que permite que se entendam e se reconheçam uns aos outros.

Os senadores defenderam o desenvolvimento econômico e a modernização social em consonância com os modelos preconizados pelos núcleos sociais, tidos como civilizados. Angela Alonso (2002, p. 392) indica que diversas teorias oriundas da Europa Ocidental e dos EUA, a exemplo do positivismo, spencerianismo, darwinismo e liberalismo, sofreram apropriações por parte dos políticos brasileiros, tendo seus usos redefinidos. Eles tomavam por referenciais a modernidade experimentada nos principais núcleos sociais desses locais, almejando se aproximar das concepções de progresso técnico, científico e social neles vigentes.

As ideias de "modernização" e de "modernidade" foram compreendidas como termos polissêmicos, percebidas a partir de sua "identificação com diferentes conceitos que determinavam suas feições e operações em diferentes momentos do processo histórico" (CARVALHO, 2012, p. 32). Depreende-se que o conceito de modernização, entre os séculos XIX e XX, conforme Marcus Vinicius Corrêa Carvalho,

\footnotetext{
$3 \mathrm{O}$ conceito de cultura política pode ser compreendido como o conjunto de valores, tradições, práticas e representações políticas compartilhadas por determinado grupo, que expressa uma entidade coletiva e fornece leituras comuns do passado, assim como fornece inspiração para projetos políticos direcionados ao futuro (MOTTA, 2009). Serge Berstein compreendeu cultura política como uma espécie de código e de um conjunto de referências, formalizadas no seio de um partido ou, mais largamente, difundidos no seio de uma família ou de uma tradição política. Elaborada e difundida a partir das instituições de formação e informação social: a família, o local, de trabalho, a universidade, os partidos, que podem ser tomados como espaços de formação cultural e política dos indivíduos (BERSTEIN, 1998).
} 
encampou ideias, práticas, representações e projetos de modernidade apropriados de maneira ideológica e aplicados, pragmaticamente, na tentativa de equiparar povos e nações que, em contextos históricos específicos eram tomados como modulares do que seja a modernidade, em termos econômicos, políticos e/ou sociais. (CARVALHO, 2012, p.26).

A modernidade seria atingida por meio do desenvolvimento econômico e social: o progresso na produção econômica e a difusão da cultura intelectual no território mineiro. Para alcançar esse objetivo, os políticos, interpretando o Estado como atrasado economicamente especialmente quando comparado à economia paulista, compartilhavam a ideia de retirar Minas Gerais de sua condição de estagnação (DULCI, 1999), e, assim, na senda para o progresso, participar do rol das nações civilizadas. Era preciso aprimorar as técnicas produtivas, dinamizar o comércio, ampliar a rede de escoamento da produção - principalmente por meio da instalação de estradas de ferro (LIMA; GOODWIN Jr., 2014) -, e qualificar a mão de obra, rompendo com o estigma da repugnância ao trabalho derivado do legado da escravidão (KOWARICK, 1987).

Porém, as ideias de modernização conviveram com práticas e instituições de programas considerados conservadores desde o Império, demonstrando o viés conservador nos discursos e na atuação dos políticos mineiros. A sociedade tradicional ainda estava presente na sociedade moderna que se formava. Constituía-se uma ideia conservadora de progresso relacionada ao tipo de sociedade que visavam construir. Percebemos, portanto, uma perenidade da tradição no processo de modernização a que se tinha em vista. Partilhava-se tanto das ideias de progresso quanto de ideias conservadoras.

Em seu estudo, Otávio Dulci (1999, p. 25-26) demonstrou que os políticos mineiros realizaram uma modernização conservadora em busca do progresso. Conforme o autor, o processo de modernização conservadora servia ao objetivo do avanço rápido: o controle autoritário dos setores subalternos e a concentração fundiária ensejavam a exploração intensiva da força de trabalho, com objetivo de recuperar o atraso econômico. O elemento central do modelo de modernização conservadora compreende a 
primazia dos fatores políticos sobre os fatores de mercado. Portanto, entre o final do século XIX e início do século XX, Minas Gerais vivenciou uma modernização relativa, em que ora sobressaíram as características da tradição conservadora, ora as características das práticas sociais modernas nos projetos legislativos instituídos (DULCI, 1999). Os políticos mineiros desse período "leram a modernização do país, considerando fortemente a aposta de intervenção do Estado na articulação e/ou moderação das forças sociais" (BOMENY, 2001, p. 20).

O progresso também era vislumbrado nos usos das tecnologias, no crescimento da produção material e na expansão das redes de comunicação (HOBSBAWM, 2011, p. 51). Nesse sentido, a condição de atraso também era definida a partir da relação de proximidade ou de distância dos modelos de produção material e cultural dos núcleos produtores e detentores de tecnologias, por exemplo. O desenvolvimento científico e tecnológico, associados ao sentido do avanço do conhecimento (PÁDUA, 2012, p.28-30), foram percebidos nos artefatos tecnológicos e nas máquinas, a exemplo do telégrafo, do telefone, da eletrificação, do automóvel, das locomotivas. Sua presença compreendia a representação de que a modernidade corresponderia à "presença de máquinas e equipamentos resultantes do desenvolvimento industrial, artefatos tecnológicos entendidos como sinais visíveis de civilização" (GOODWIN JR., 2015, p. 25).

O progresso e a modernização almejados tinham seus referenciais nas experiências dos núcleos sociais da Europa Ocidental e dos Estados Unidos da América. Desejava-se aproximar das concepções de progresso técnico, científico e social vigentes nesses lugares - percebidos como modelos mundiais na "esteira da expansão capitalista". Desse modo, Paris, Viena, Londres e Nova York, entre outras, eram as cidades-síntese desse novo mundo que surgia (GOODWIN Jr., 2015, p.83). Modelos e vitrines de uma imagem do progresso, essas cidades foram locais de produção de aparatos tecnológicos e de costumes sociais associados a um ideal de modernidade.

A busca pelo progresso passou a tornar-se cada vez mais relevante no Brasil após 1850. A partir desta época, com a consolidação do regime 
monárquico, o fim das rebeliões e do tráfico negreiro, o consequente incremento dos negócios com a Inglaterra, o país teve um significativo desenvolvimento econômico por meio da produção cafeeira. O progresso econômico foi acompanhado pelo crescimento de centros urbanos, pela expansão da rede ferroviária, pelo uso do telégrafo e o uso de maquinários na incipiente indústria de transformação - incrementando a atividade comercial (CARVALHO, 2002).

Adentrar o rol das nações desenvolvidas e modernas também significa a busca pelo progresso econômico, especialmente o desenvolvimento ligado ao industrialismo. A elite nacional vislumbrava nos exemplos de França, Inglaterra, Alemanha, Bélgica, Áustria, Holanda e Suíça padrões a serem tomados como paradigmas dos caminhos para a modernização. Raymundo Faoro (2012, p. 457) demonstra essa ideia:

O país europeizava-se, para escândalo de muitos, iniciando um período de progresso rápido, progresso conscientemente provocado, sob moldes ingleses. O vestuário, a alimentação e a mobília mostram, no ingênuo deslumbramento, a subversão dos hábitos lusos, vagarosamente rompidos com valores culturais que a presença europeia infiltrava, juntamente com as mercadorias importadas. [...] Ao Estado, a realidade mais ativa da estrutura social, coube o papel de intermediar o impacto estrangeiro, reduzindo-o à temperatura e à velocidade nativas.

O progresso havia se tornado o leitmotiv da busca pelos processos civilizatórios, que resultaram em esforços para adequar-se aos padrões culturais da Europa Ocidental, especialmente Inglaterra e França. A condição de proximidade ou distância desses padrões difundia a imagem de civilização ou barbárie das sociedades. O excerto de Eric Hobsbawm é explicativo ao identificar que a procura do status de civilização ainda estava, também, presente em sociedades da Europa:

Por volta de 1880, predominavam no mundo "desenvolvido" países ou regiões em que a maioria da população masculina e, cada vez mais, feminina era alfabetizada; onde a vida política, econômica e intelectual, de maneira geral, havia se emancipado da tutela das religiões antigas, baluartes do tradicionalismo e da superstição; e que praticamente monopolizavam o tipo de ciência que era cada vez mais essencial à tecnologia moderna. No final 
dos anos 1870, qualquer país ou região da Europa que contasse com uma maioria de analfabetos quase certamente podia ser classificada como não desenvolvida ou atrasada, e vice-versa. (HOBSBAWM, 2011, p. 48).

O progresso estava associado à ideia de ordem. Para os políticos mineiros, a República seria a única opção viável para dar prosseguimento à sua procura; mas, era preciso a aplicação da ordem. A preocupação com a manutenção do equilíbrio social era uma constante entre os políticos mineiros e nacionais, sendo corrente a crença no ideal do ordenamento da sociedade como um dos propulsores para o seu desenvolvimento econômico e social. A ideia de ordem, assim, tornou-se mote da bandeira nacional. Sua aplicação era entendida como condição da possibilidade do engrandecimento mineiro.

Nos dizeres do senador Afrânio de Mello Franco, na $3 \cdot^{\mathrm{a}}$ sessão ordinária de 09 de julho de 1891, o progresso deveria ser alcançado dentro de uma ordem estabelecida na sociedade, de modo "lento e contínuo" (ANAIS DO SENADO MINEIRO, 1891-1892, p. 95). Affonso Augusto Moreira Penna também percebia na instituição da ordem pública elemento primordial para manutenção da estabilidade social. Alcançar o progresso de modo "lento e contínuo" correspondia ao desejo de incutir às massas, especialmente aos libertos, uma nova postura social, voltada para a valorização do trabalho e ensino das noções de "cidadania". Conforme a análise dos debates do Senado Mineiro, ficou demonstrado que, para os políticos que o compunham, havia a necessidade de difundir o conhecimento sobre as leis, os códigos de posturas e higiene ainda que de forma rudimentar, por exemplo, entre os brasileiros.

Por intermédio de uma ação política coordenada e da expansão regulatória do governo do Estado, empregaram medidas ora centralizadoras ora liberais, com intuito de trazer Minas Gerais para o caminho do progresso, da civilização e da ordem - percebida como manutenção da estabilidade social e política (FERES JR.; SÁ, 2014, p. 219-220). Para Eliana de Freitas Dutra (2005, p. 200), o discurso civilizatório, além de "influenciar a erudição, o pensamento social, a imaginação política, coage à adoção de diretivas políticas, de um padrão de valores e de práticas sociais”. Essa 
afirmação pode ser confirmada nas palavras do senador Joaquim Cândido da Costa Senna:

A educação, todos sabem, consiste em certos hábitos morais e físicos que se impõem às crianças, logo que atingem ao uso da razão; esta pertence principalmente a família. A instrução, porém Sr. Presidente, que chamamos - primária, deve sempre correr por conta do Estado, porque é essa instrução que abre aos meninos as portas de seus direitos, deveres e interesses; é esta instrução que é a destinada a fazer do menino um cidadão. O Estado, a meu ver, é obrigado a dar às crianças um mínimo de instrução, um mínimo que lhe é indispensável à compreensão de seus direitos, de seus deveres e de seus próprios interesses. (ANAIS DO SENADO MINEIRO, 1892, p. 188-189).

A organização da instrução pública e profissional, como parte de um projeto de disciplinamento e ordenamento da sociedade, estava presente nos discursos dos políticos mineiros. Era necessário garantir a continuidade produtiva e desvincular a imagem negativa do trabalho manual, associado ao trabalho realizado por cativos. Essas ideias articularam o discurso do trabalho como um dos caminhos para o progresso. Como exemplo, o discurso do senador Affonso Penna é elucidativo sobre a importância concedida às instituições de formação profissional no imaginário político mineiro. Ao sugerir a relevância da criação de institutos de formação profissional, especialmente ligados ao ensino agrícola, manifestou sua compreensão quanto às necessidades econômicas mineiras:

Acredito que outros institutos congêneres hão de ser criados pelo Congresso Mineiro, porque nós não precisamos de educação literária: precisamos, antes de tudo, de instrução profissional e técnica. (Apoiados). As condições do Estado Mineiro são as mais apropriadas para o desenvolvimento da lavoura e das indústrias; mas estas principais fontes de riqueza, não se poderão desenvolver convenientemente, enquanto não criarmos institutos, que formem cidadãos com a instrução precisa para explorá-las. (ANAIS DO SENADO MINEIRO, 1891-1892, p. 296).

O progresso material não era fator suficiente para alcançar o engrandecimento mineiro, os ideais de modernidade vislumbrados. Os discursos dos políticos mineiros, ao longo de todo o século XIX e início do século XX, sugeriram a articulação entre a instrução pública e profissional 
e desenvolvimento econômico (FARIA FILHO; GIL; ZICA, 2012, p. 9). Sobremodo, a escolarização foi imaginada como um dos elementos chaves para progresso, percebida como um instrumento de mudança social e meio civilizador. O discurso do senador Afrânio de Mello Franco é elucidativo sobre essa questão:

O que nós atualmente precisamos fazer é desenvolver a riqueza pública, criando escolas profissionais e agrícolas, etc., devemos procurar lançar a instrução por todas as camadas sociais, porque a maior parte da população, no Brasil, é analfabeta. [...] Dois elementos concorrem para desenvolver a riqueza pública - elevar a produção pelo maior número de membros da sociedade, que se ocupam de trabalho útil e pelo desenvolvimento da inteligência nacional, dividindo-o, inventando máquinas, etc., e convertendo em seu proveito as forças da natureza. (ANAIS DO SENADO MINEIRO, 1891-1892, p. 719).

Os políticos mineiros, ao se referirem aos projetos de organização da instrução pública, em destaque a instrução profissional, revelavam a apreensão e utilização de repertórios reproduzidos e produzidos na tessitura dos seus discursos, voltados para o progresso mineiro, por meio da instrução pública e formação do trabalhador. Eles apropriavam-se e reapropriavam-se de diferentes modelos para legislar sobre a escolarização, alterando-os conforme suas deliberações para compreender determinadas situações e mobilizar sua atuação. Os senadores, como os demais políticos mineiros, apresentaram a ideia de que esse avanço seria alcançado ao civilizar e instruir a população para o trabalho; fomentar a economia comercial; aprimorar os métodos agrícolas, implantar o industrialismo, ligado à agropecuária, e expandir as vias de comunicação do estado, sobretudo com a instalação de estradas de ferro (PÁDUA, 2012).

\section{A instrução pública e profissional nos repertórios dos discursos políticos}

Desde a proclamação da Independência no país, em 1822, os políticos brasileiros, ao pensarem no projeto de modernização da sociedade, 
perceberam a instrução como a principal mola propulsora. Conforme os ideais iluministas, presentes no pensamento dos políticos mineiros, esta questão estava diretamente ligada à escolarização da população pobre e livre. Para Claudia Viscardi (2012, p. 65), os projetos de construção da identidade e da unidade nacional foram "alimentados por referências a países estrangeiros, entre os quais, destacou-se primeiramente o continente europeu, como espelho para o Brasil, e, posteriormente os EUA, sobretudo a partir da década de 1870”. De acordo com Carla Chamon (2005, p.178), os EUA começaram a ser percebidos como referência na área da instrução, por apresentarem um sistema de ensino mais sólido e mais amplamente distribuído pela população.

É pertinente ressaltar que a presença da influência cultural dos Estados Unidos da América tornou-se mais forte no Brasil a partir de 1870, como pode ser percebido no seguinte excerto do Manifesto do Partido Republicano: "Somos da América e queremos ser americanos" (CARVALHO, 1998; ALONSO, 2002). Apesar da nítida influência dos EUA nestas ideias, é necessário indicar que a República era entendida como um regime "natural” da América, o "novo mundo", onde os países vizinhos do Brasil já adotavam esse modelo de governo, em contraposição à monarquia, instituição do "velho mundo europeu". José Murilo de Carvalho, ao analisar o Manifesto Republicano de 1870, destaca a presença desta ideia na corrente política nacional. Segundo o autor, o manifesto, em um de seus argumentos, apontava para o isolamento do Brasil na América, pois "a América era a República” (CARVALHO, 2013, p. 146). Percebemos a alusão ao modelo de desenvolvimento apregoado nos EUA, por meio da afirmação de que

o americanismo no Brasil pode ser interpretado em sua função de dar status a determinados fatos institucionais; ou ainda, como discurso que pretendeu dar a determinadas ideias o status de pertencentes à modernidade e ao progresso. [...] A credibilidade que o progresso material dos Estados Unidos da América outorgava ao país fez com que se tornassem modelo a ser seguido. [...] A questão era o progresso técnico e material: cidades agitadas, indústrias bem desenvolvidas, máquinas e invenções de todos os tipos abrindo novas possibilidades de vida. [...] Se há admiração pela industriosidade americana e pelos resultados por ela produ- 
zidos, certamente é porque eles estão em sintonia com um determinado horizonte de futuro a que se deseja alcançar. (SILVA, 2015, p. 73-87).

Carla Chamon (2005, p. 170-171) assinala que, nesta época, "a influência norte-americana já pode ser notada em duas esferas de grande importância para o país": a esfera política e a esfera educacional. Nesse sentido, assim como modelos civilizatórios europeus, podemos auferir que o americanismo, enquanto discurso, já estava articulado em território nacional ao final do século XIX. Logo, a partir da instalação da República, houve ainda maior predomínio das ideias culturais vindas dos EUA a inspirar o pensamento da elite dirigente brasileira. Portanto, as ideias, tomadas de empréstimo a diversos núcleos sociais da Europa e dos EUA, corresponderam a repertórios apreendidos e circulantes na cena política mineira.

A instrução, portanto, foi considerada um ramo fundamental da administração pública "no momento em que se impôs a necessidade de formar pessoas dotadas de novas qualidades, fundamentais à constituição do Estado Imperial", segundo o projeto de civilização e modernização visado (INÁCIO; FARIA FILHO; ROSA; SALES, 2006, p. 15). Depreende-se que havia forte preocupação em formar quadros dirigentes e formar a força de trabalho, para desenvolver as principais fontes de riqueza de Minas Gerais; "instrumentalizando as pessoas para as mais variadas funções, por meio da instrução, o que colocou a escolarização também como base para o desenvolvimento" (Ibidem). Essa afirmação pode ser confirmada na mensagem do Presidente da Província de Minas Gerais em 1828:

Tudo vence a inteligência e a mão do homem civilizado. A França, Inglaterra, Alemanha, e quase toda a Europa, centro agora das ciências, artes, e indústria, comércio e civilização, estavam há alguns séculos submersas em barbárie e bruteza. Sim, nossas diligências poderão [...] por estradas [...] presentemente intransitáveis, traspassar com pontes rios [...], arrancar das entranhas dos montes prenhes de todos os metais [...]; melhorar a agricultura [...], animar a indústria, dilatar o comércio, extirpar abusos que impedem o andamento dos negócios úteis; aligeirar com inventos, e maquinaria o peso dos trabalhos, multiplicando as potências produtivas, aumentar progressivamente os capitais, e a par 
deles a população; verificar o gérmen dos talentos com que a natureza dotou os nossos concidadãos; e exercitar a instrução pública, na razão direta da qual se promove a civilização, grandeza, e opulência dos Estados. (João José Lopes Mendes Ribeiro, 1828, apud LAGES, 2013, p.17).

Participar do rol das nações civilizadas era uma das metas dos políticos mineiros e nacionais, desde antes de $1822 .{ }^{4}$ A civilidade era considerada uma virtude europeia, pela qual predominaria o comportamento de polidez, educação e boas maneiras. Buscar o status de sociedade civilizada significava promover o ignorante, por meio da urbanização e da educação, ao estado civil; isto é, viver ordenadamente sob a égide das leis e da moral cristã (FERES JR,; SÁ, 2014, p. 214). Rita Cristina Lages (2014, p. 65) afirma que, após a proclamação da Independência, a elite dirigente brasileira desenhava um projeto de modernização da sociedade, cujas referências eram os principais núcleos sociais da Europa. O seguinte excerto de Ilmar Rohloff de Mattos (1987, p. 1) expõe o comportamento dessa elite nacional, que buscava no estrangeiro os repertórios necessários para organizar o novo Estado:

No parlamento, nas casas, nos pasquins e até mesmo nas ruas e praças públicas, aqueles que pretendiam dirigir os destinos de uma sociedade que julgava ter completado sua emancipação da tutela metropolitana, expunham suas ideias e seus programas, procuravam viver seus sonhos e utopias, expressavam seus temores e angústias. Servindo-se de imagens e conceitos cunhados em países distantes, buscavam referências para a compreensão do quadro em que se moviam, assim como procuravam ser semelhantes às nações que se apresentavam como portadoras de uma civilização.

Durante os anos iniciais da República, o projeto de escolarização também foi interpretado como elemento para a construção da nação que se formava e do projeto de Estado que se pretendia construir, especial-

\footnotetext{
4 Conforme José Murilo de Carvalho (1998, p. 90), ideias e instituições norte-americanas e europeias já tinham sido adaptadas por políticos imperiais. Antes mesmo da independência do país, rebeliões coloniais tinham-se inspirado na revolução americana e na revolução francesa.
} 
mente após a abolição. Havia forte crença na eficácia da escola como "viabilizadora da produção e reprodução das formas sociais de vida e de inclusão do sujeito na sociedade, por meio da divulgação da instrução intelectual, física e moral" (GONÇALVES, 2012, p. 18). Os discursos dos políticos mineiros demonstraram que, em sua maioria, a instrução foi percebida como um dos importantes fatores para o desenvolvimento social, também entendida como um instrumento de mudança social e meio civilizador. De acordo com Irlen Antônio Gonçalves (2009 apud PÁDUA, 2012, p. 75),

[...] há uma íntima relação entre a educação escolar como instrumento transformador da sociedade e as propostas de constituição de uma nação civilizada, baseada na ideia de progresso, presentes nos discursos dos intelectuais e políticos mineiros, nas primeiras décadas da República.

Os políticos mineiros conceberam para o Estado a missão pedagógica de instruir a população, além da formação profissional, moral e culturalmente. Cabia ao ensino mineiro incorporar uma perspectiva mais ampla, "que ultrapasse a simples instrução escolar" (GONÇALVES, 2012, p. 27). A escolarização deveria contemplar a formação cívica e moralizadora e o ensino para o trabalho, cuja função seria formar cidadãos adequados ao tipo de República que objetivavam construir. Como um dos pressupostos do projeto de modernização, o projeto de instrução pública e profissional se cumpriria na criação da identidade do indivíduo por meio do trabalho, a partir do trabalho livre com qualificação técnica, resultante de um processo educacional racionalmente estruturado e competentemente administrado (DULCI, 1999, p. 161).

Conforme Renata Fernandes Andrade (2007, p.24), a quantidade de Leis e Regulamentos publicados no período demonstra o caráter pedagógico das legislações, que manifestavam um ideal a ser realizado: difundir, por meio da instrução, "os hábitos e os costumes considerados modernos e civilizados". Ainda segundo a autora, a "Lei ordenaria as relações sociais, bem como civilizaria a população”. Por isso, era necessária a mobilização de busca de estratégias "que visavam não apenas criar novos instrumentos de controle social”, mas também, adequar as condutas "às exigências co- 
locadas pela marcha da civilização e do progresso”. No interior das discussões da criminologia, pensava-se numa educação moral para as crianças que ainda não haviam cometido crimes, mas que representavam potenciais riscos de ingressar à delinquência.

A reforma da educação teve, como um de seus princípios norteadores, a preocupação com a função educativa da escola na formação do caráter da criança. A defesa do caráter formativo da educação coincide com as posições de outros intelectuais brasileiros e mineiros, principalmente advogados e médicos. Segundo Marcos César Alvarez (2003, p. 158), houve, nos tempos iniciais da República, forte preocupação com a crescente pobreza urbana e com o aumento significativo do número de crianças pobres, abandonadas e delinquentes. Logo, a formação profissional, ou ensino pelo e para o trabalho, destinava-se às crianças delinquentes, oferecida nos espaços das oficinas. Para Otavio Dulci (1999), a educação para o trabalho seria realizada em duas situações: por meio do ensino profissional, nas escolas, e da instrução prática de trabalhadores adultos.

O interesse republicano pela implantação do processo de formação profissional no Estado foi se materializando a partir da Lei ${ }^{\circ}$ 41, de 1892, quando se instituiu o ensino profissional no âmbito das escolas normais, do ensino agrícola e zootécnico, do curso de agrimensura, comercial e de farmácia5. Destaca-se que nos primeiros dez anos do regime republicano em Minas Gerais foram encontradas onze leis que tramitaram no Congresso e tiveram por objetivo a reforma ou a modificação da instrução pública (GONÇALVES, 2010; 2011). 6 Tais modificações ocorreram principal-

\footnotetext{
5 A Lei n. 41 tramitou no Congresso Legislativo, a partir da Câmara dos Deputados, e foi apresentada pela comissão de instrução pública em setembro de 1891, dois meses após a decretação e promulgação da Constituição do Estado de Minas Gerais. Mesmo sendo considerada uma lei ampla e complexa por ter que contemplar os vários níveis da instrução pública (primária, secundária, superior e profissional) e por ter que se adequar às novas formas de organização da República, o seu tempo de tramitação teve uma duração curta de somente onze meses.

${ }^{6} 1$. Lei n ${ }^{0} 41$ - de 3 de agosto 1892 - Dá nova organização à instrução pública do Estado de Minas; 2. Lei $\mathrm{n}^{0} 73$ - 27/07/1893 - Autoriza o governo do estado a pôr gradativamente em execução as disposições da lei no 41 de 3 de agosto de 1893 , relativa ao ensino
} 
mente na instrução pública primária. $\mathrm{O}$ ensino profissional, primeiramente, estava relacionado à indústria agrícola, de modo que os primeiros debates se voltaram para o estabelecimento de Escolas Práticas Agrícolas. As leis que sucederam a Lei n. 41 foram produzidas com o intuito mais de aprimorá-la do que propriamente modificá-la. As alterações ocorreram mediante argumentação de que serviriam para promover a melhoria da situação de degradação em que se encontrava o ensino em Minas (GONÇALVES, 2010; 2011).

Em defesa dos projetos de instrução pública que procuravam instituir, recorreram aos repertórios intelectuais disponíveis referentes a forma de organização da educação pública. Em relação à instrução pública destaca-se a presença do repertório político-intelectual europeu, especialmente o francês, e dos EUA. O discurso do senador Afrânio de Mello Franco, na $8^{\mathrm{a}}$ sessão ordinária do Senado Mineiro, de 17 de julho de 1891, fornece um vislumbre do pensamento político mineiro sobre o assunto:

Na vida social vimos que, quando um grupo étnico é mais desenvolvido de que outro e consegue pelo progresso colocar-se em posição superior, torna-se uma espécie de modelo ao qual todos procuram imitar. Eis porque nos EUA e na Alemanha encontramos uma legislação com todas as tendências para a uniformidade. Assim os povos caminham para a unificação pela cópia das instituições semelhantes, e não pela expansão de autonomia da

agrícola e zootécnico, expedindo o respectivo regulamento, e a subvencionar as municipalidades que fundarem e mantiverem fazendas modelo, escolas agrícolas, industriais ou pastoris, estações agronômicas, etc.; 3. Lei $n^{0} 77$ - de 19 de dezembro de 1893 Divide o Estado em 10 circunscrições literárias, tendo por sede as cidades em que há Escolas Normais. - Altera diversas disposições da lei $\mathrm{n}^{0} 41$ de 3 de agosto do ano passado e dá outras providências; 4. Lei no 103 - 24/07/1894 - Autoriza o Presidente do Estado a fundar duas escolas agrícolas nas cidades de Oliveira e Entre Rios; 5 . Lei $\mathrm{n}^{\mathrm{o}}$ 104 - 24/07/1894 - Cria junto a cidade do Curvelo, uma fazenda escola, destinada ao ensino prático de agricultura e indústria pastoril, e contém outras disposições a respeito; 6. Lei $\mathrm{n}^{0} 140$ - 20/07/1895 - Reforma o ensino agrícola e zootécnico do Estado; 7. Lei de $\mathrm{n}^{0} 203$ - de 18 de setembro de 1896 - Organiza o ensino profissional primário; 8. Lei $\mathrm{n}^{0} 221$ - de 14 de setembro de 1897 - Contém disposições relativas à instrução pública primária e secundária; 9. Lei $\mathrm{n}^{\circ} 234$ - de 27 de agosto de 1898 - Regula a substituição dos lentes e professores dos estabelecimentos de ensino e contêm outras disposições; 10. Lei ${ }^{0} 259$ - de 10 de agosto de 1899 - Cria cadeiras de instrução primária em diversas localidades; 11 . Lei no 281 - de 16 de setembro de 1899 - Dá nova organização à instrução pública do Estado de Minas Gerais. 
personalidade humana. Esta é uma fase mais adiantada da civilização, a que havemos de chegar. Vamos nos colocar no ponto de partida em que nos achamos, considerando o povo como ele é atualmente, segundo suas condições e seu estado de desenvolvimento. (ANAIS DO SENADO MINEIRO, 1891-1892, p. 95).

Verificou-se que durante as discussões entre os senadores, recorriase aos projetos políticos instituídos no exterior, aos grandes nomes da política internacional, para validar, fundamentar ou criticar uma argumentação. Como exemplo, observamos o senador Afrânio de Mello Franco citar a organização da instrução profissional agrícola da França. O modelo era dividido em "écoles nationales", instituições de formação superior, "écoles pratiques", de nível intermediário, correspondiam à formação técnica de nível secundário, e as "fermes-écoles", notadamente frequentadas por camponeses, correspondiam ao ensino elementar (PERECIN, 2004).

As intepretações dos repertórios provenientes do estrangeiro não tinham por objetivo a construção de determinadas teorias narrativas nem a reprodução de sistemas teóricos, foram utilizadas, em diversas situações, para legitimar a argumentação política. Sua origem não limitava a experiência pessoal direta, os repertórios chegavam ao país e a Minas Gerais, por meio de revistas, jornais, livros e publicações científicas. Os políticos mineiros não pretendiam reproduzir os modelos vislumbrados no Estado. Eles se preocupavam em adequar tais modelos à realidade sociocultural de Minas Gerais. Alguns senadores mostraram-se avessos à prática de importar modelos institucionais, como o senador Francisco Silviano de Almeida Brandão quando afirmou que

Apesar da boa vontade dos administradores, apesar dos bons desejos manifestados pelas antigas assembleias provinciais, as quais foram até pródigas na criação de escolas primárias, nada temos feito que nos traga glória, sendo certo que os resultados obtidos, quase que negativos não tem compensado os sacrifícios, aliás enormes, feitos pelo Estado. [...] Seja-me, porém, permitido aqui consignar, que uma das causas do nosso atraso, a meu ver, em matéria de ensino, consiste no espírito de imitação inconsciente, por parte dos brasileiros em geral; apreciamos os programas pomposos, embora inexequíveis; somos fascinados pelo ensino integral, embora impossível. [...] Este espírito de imitação, 
esta tendência que temos de fazer leis e regulamentos espetaculosos, para ficarem somente no papel, não produzindo resultados práticos, é o que nos mata. (ANAIS DO SENADO MINEIRO, 1891-1892, p. 377-378).

Ao discutir a normatização da instrução pública, muitos senadores passaram a defender o ensino profissional como meio mais eficaz de desenvolver economicamente o Estado. Ao contrário da cultura literária, que a sociedade anteriormente presava, o ensino deveria atender as necessidades materiais e científicas do período, voltar-se para o aprimoramento das técnicas industriais e para o aprendizado das mesmas. $\mathrm{O}$ discurso de Affonso Augusto Moreira Penna, quando senador mineiro, pode ser tomado como exemplo, devido às argumentações apresentadas durante o encaminhamento do projeto da primeira lei que propunha reformar a instrução pública no Estado:

Nós não precisamos de educação literária: precisamos antes de tudo, de instrução profissional e técnica. (Apoiados). As condições do Estado Mineiro são as mais apropriadas para o desenvolvimento da lavoura e das indústrias; mas estas principais fontes de riqueza, não se poderão desenvolver convenientemente, enquanto não criarmos institutos, que formem cidadãos com a instrução precisa para explorá-las. (ANAIS DO SENADO MINEIRO, 1891-1892. p. 296).

Affonso Penna não foi o único político a advogar pela necessidade de criar institutos de ensino profissional no Estado. Além de seu discurso, podemos destacar o pronunciamento do senador Afrânio de Mello Franco, em concordância com suas ideias:

Facilitando aos meninos pobres das classes rurais, a esses que são atualmente os instrumentos do trabalho agrícola, os agentes diretos da lavoura, os cultivadores do nosso solo, a instrução elementar necessária para a profissão a que se destinam. Sr. Presidente, o Sr. Conselheiro Afonso Pena, fez sentir, há dias, quanto é deficiente, entre nós, o ensino técnico e profissional: porquanto até hoje não temos tratado senão da educação clássica, que prepara alunos para as faculdades de direito e outras: mas estes moços ficam inutilizados para qualquer outra carreira industrial [...] Era, pois, preciso corrigir esta educação, dando aos brasileiros o ensino técnico e profissional, porque agora é que começa a desenvolver-se a indústria no Estado, aumentar a riqueza pública e 
desenvolver, por modo extraordinário, a atividade industrial. Portanto, o ensino deve acompanhar esta evolução. S. Exc. demonstrou a necessidade do ensino técnico e profissional. (ANAIS DO SENADO MINEIRO, 1891-1892, p. 306).

Apesar do interesse em instruir a população e qualificar o sujeito para o trabalho, foi possível identificar que os políticos mineiros buscavam instruir minimamente os trabalhadores rurais, por meio das escolas práticas. Nesse sentido, aos agricultores seria fornecido o ensino elementar para o manejo da terra, sendo transmitido noções rudimentares de agronomia. Para difundir o ensino agrícola no Estado, "facilitando a aprendizagem" dos agricultores, os projetos que receberam maior apoio dos senadores voltavam-se para a instrução prática e elementar daqueles que trabalhavam com a terra.

O intento de estabelecer uma escola nos mais modernos modelos de ensino e de instituições, notadamente importados dos países considerados cultos e civilizados, não se concretizou. Em consonância com o pensamento da época, muitos políticos acreditavam que a organização da instrução pública e profissional deveria ser adequada ao tipo de sociedade em que se instalaria. Nesse sentido, ao perceberem a sociedade mineira como atrasada culturalmente, apoiaram o emprego de um projeto de escolarização mais simplificado, conforme o nível intelectual dos mineiros, a exemplo do discurso do senador Afrânio de Mello Franco:

Cumpre que confessemos a triste verdade do estado de atraso em que estamos, e não será de um momento para o outro que havemos de fazer de um povo atrasado e quase analfabeto um povo civilizado pelo simples milagre de uma legislação adiantadíssima sobre instrução pública; mas legislação que desconhece ou não tem em vista as condições históricas do povo que é destinada. Esta legislação seria aplicável para a Itália, para a França, para a Alemanha e nunca para o Estado de Minas Gerais. (ANAIS DO SENADO MINEIRO 1892, p. 76).

Ao final do século XIX, o Estado de Minas Gerais perpassou por forte crise financeira, o que inviabilizou a instituição de um projeto mais amplo no âmbito da instrução pública e da formação profissional. A reforma do ensino público, instituída pela Lei n. 41 de 1899, estabelecia o 
enxugamento das escolas normais e a supressão das escolas rurais. Apesar de vários protestos contra a medida, a lei foi aprovada e várias escolas fechadas pelo território mineiro.

A avaliação dos discursos dos senadores permite inferir quais repertórios foram apreendidos, reproduzidos e produzidos na conjuntura das relações políticas, sociais e culturais, na qual estão inseridos. O conceito de repertório possibilita compreender a quais ideias políticas eles recorreram para empreender suas ações no plano educacional. Por considerarem Minas Gerais um estado voltado para a produção de base agrícola, os senadores procuraram criar estabelecimentos de aprendizagem agrícola (DULCI, 1999, p. 131) e ampliar o ensino primário, destinado a formação cidadã do sujeito trabalhador.

\section{Considerações finais}

Os discursos dos políticos mineiros revelam sua interpretação da instrução pública, especialmente sobre o ensino profissional, como um dos principais instrumentos para se atingir os ideais de progresso, modernização e civilização. Nos debates políticos percebemos forte crença na eficácia da escola como fator de transformação social. A constituição de uma sociedade moderna, conforme as expectativas relacionadas à sua organização, estava associada ao avanço da produção econômica por meio da instituição da instrução profissional. Era evidente a expectativa entre os políticos mineiros quanto à instituição do ensino profissional como argumento estratégico, que integrava grande parte dos projetos de Estado-nação, definidos conforme a noção de ordem e de progresso sociais. A escola serviria de resposta às múltiplas demandas da modernidade: ampliação das habilidades humanas úteis à economia e a formação de indivíduos e de sociedades "melhores e mais civilizados" (VISCARDI, 2012).

O interesse pela construção de uma nova ordem social e política colocava em evidência o processo de escolarização como forma de produzir e fortalecer o Estado Republicano. Nesse sentido, a importância dada à 
instrução pública demonstrou o quanto significou, para o projeto de sociedade que se preconizava, a escolarização, em especial do ensino profissional, pensada como prática social de incorporação do indivíduo à sociedade. O Estado mineiro, porém, investiu, segundo suas possibilidades econômicas, na viabilização das condições para a implantação de uma educação e de uma instrução que contribuíssem para a constituição da ordem e do progresso.

Ao mapear a rede de sociabilidades articulada na política mineira, ideias e projetos relativos à instrução da população foram compreendidos como "necessários à concretização de uma modernidade aspirada (e sonhada), cuja preocupação consistia em civilizar hábitos e costumes tidos como centrais na condução do progresso" (VALLE; HAMDAN; DAROS, 2014, p. 13). Os discursos demonstraram o "pressuposto iluminista de superar o atraso pelo saber, que esteve presente em diversas iniciativas de escolarização, públicas e particulares, encetados em momentos diversos do processo de desenvolvimento mineiro" (DULCI, 1999, p. 130).

A instrução pública e profissional, vista como fator de civilização e progresso, era percebida como recurso para manter a ordem social ou prevenção ao crime: uma nação inserida no espírito da civilização, instruída, educada e orientada para o progresso da indústria deveria ser uma nação ordeira, logo uma nação educada. Assim, ao Estado caberia o dever de fornecer a instrução ao povo (VISCARDI, 2012). Desse modo, a instituição de ensino ocupava um lugar estratégico no imaginário político, ao integrar grande parte dos projetos de Estado-nação, definidos conforme a noção de ordem e de progresso sociais. A escola servia de resposta às múltiplas demandas da modernidade: ampliação das habilidades humanas úteis à economia e a formação de indivíduos e de sociedades "melhores e mais civilizados" (VISCARDI, 2012).

A falta de escolaridade acarretaria na elevação das estatísticas criminais. Muitos senadores apontaram a escola como um meio de diminuir a criminalidade, pois a profissionalização dos jovens forneceria a oportunidade para ingressarem na sociedade, contribuindo para o estado de ordem e o progresso da nação. As crianças pobres, "desvalidas da sorte e da fortuna”, também receberam atenção dos políticos mineiros, que percebiam 
a educação como o instrumento capaz de habilitá-las para a vida em sociedade e a instrução profissional como a maneira de torná-las futuros trabalhadores produtivos. O modelo de escola adotado para as crianças pobres, portanto, assumiria um caráter prático, e não literário (GONÇALVES, 2012, p. 77) e atenderia as demandas do progresso.

Presente nos discursos parlamentares, a instrução foi compreendida como "única ferramenta capaz de garantir o progresso contínuo, o desenvolvimento e a civilização" (VISCARDI, 2012, p. 13). O progresso estaria relacionado ao avanço da cultura intelectual por meio da difusão do ensino primário e instituição do ensino profissional (GONCALVES; NOGUEIRA, 2012). A instrução e a educação do povo possibilitariam o desenvolvimento social, sendo que a formação técnica seria o meio de aprimorar a produção e promover os avanços almejados na economia mineira. O ensino profissional foi propugnado como um dos meios de se chegar ao progresso, que viabilizaria a entrada do Brasil no rol das nações modernas.

O ideal de progresso por meio da educação foi compartilhado pelos políticos mineiros. Para organizar a instrução pública no Estado, apropriavam-se dos repertórios disponíveis na cena política mineira, nacional e internacional. Eles reproduziram e produziram repertórios, selecionados no amálgama das ideias circulantes do período sobre ensino público e instrução profissional. As discussões sobre instrução pública foram construídas perpassadas pelas noções de progresso, em que conceitos e teorias foram utilizados seletivamente, segundo uma intencionalidade própria, para defender ou refutar determinada argumentação e delimitar formas de ação.

Na circulação de repertórios e argumentos referentes aos programas de instrução e formação do trabalhador destacam-se as noções apreendidas dos núcleos da Europa Ocidental e dos Estados Unidos da América, como modelos a serem seguidos. Destarte, na competição entre as nações, o ensino, público e profissional, foi pensado como parte de uma estratégia que promoveria o desenvolvimento econômico e social, pressupostos de uma sociedade moderna e civilizada, do povo que o detivesse. 
Affonso Penna, Afrânio de Mello Franco, João Pinheiro, entre outros defensores da instituição do ensino profissional em Minas Gerais; perceberam a condição do progresso associada às melhorias materiais, sendo essas garantidas pelo progresso da indústria - que necessitava de mão de obra minimamente qualificada. Para os políticos mineiros, o progresso material mostrava-se insuficiente para alcançar o engrandecimento mineiro, era preciso conjugá-lo ao desenvolvimento social e à formação técnica do trabalhador, possibilitados pela instrução pública e profissional. Seria por meio da educação, a partir do desenvolvimento econômico e social, que Minas Gerais encetaria seu processo de modernização e adentraria ao rol das nações civilizadas.

\section{Referências}

ABBAGNANO, N. Dicionário de Filosofia. 6 . $^{\text {a }}$ ed. São Paulo: Editora WMF Martins Fontes, 2015.

ALONSO, A. Idéias em movimento. A geração 1870 na crise do Brasil-Império. Rio de Janeiro, Paz \& Terra/Graal, 2002.

ALVAREZ, M. C. Bacharéis criminologistas e juristas: saber jurídico e nova Escola penal no Brasil. São Paulo: Método, 2003.

ANDRADE, R. F. M. Organização da instrução na Província de Minas Gerais: da Legislação aos Relatórios dos Presidentes (1850-1889). Dissertação (Mestrado) - Universidade Federal de Uberlândia, Uberândia 2007. BERSTEIN, S. A cultura política. IN: RIOUX, J.-P.; SIRINELLI, J.-F. (org.). Para uma história cultural. Lisboa: Estampa, 1998.

BOMENY, H. (org.) Constelação Capanema: intelectuais e políticas. Rio de Janeiro: Editora FGV, 2001.

CAPELATO, M. H. Os arautos do liberalismo: imprensa paulista, 19201945. São Paulo, Brasiliense, 1989.

CARVALHO, J. M. A Construção da ordem e Teatro das sombras. Rio de Janeiro: Editora Civilização Brasileira, 2013.

. Cidadania no Brasil. O longo Caminho. $3{ }^{\mathrm{a}}$ ed. Rio de Janeiro: Civilização Brasileira, 2002. 
. Pontos e bordados. Escritos de História e Política. Belo Horizonte: Editora UFMG, 1998.

CARVALHO, M. V. C. Moderno, modernidade, modernização: polissemias e pregnâncias. In: FARIA FILHO, L. M.; GIL, N.; ZICA, M. C. Moderno, modernidade e modernização: a educação nos projetos de Brasil - séculos XIX e XX. Vol. 1. Belo Horizonte: Mazza Edições, 2012.

CHAMON, C. S. Maria Guilhermina Loureiro de Andrade: a trajetória profissional de uma educadora (1869-1913). Tese (Doutorado) - Universidade Federal de Minas Gerais, Belo Horizonte, 2005.

CHARAUDEAU, P. Discurso político. São Paulo: Contexto, 2013.

DULCI, O. S. Política e recuperação econômica em Minas Gerais. Belo Horizonte, Editora UFMG, 1999.

DUTRA, E. F. Rebeldes literários da República: história e identidade nacional no Almanaque Brasileiro Garnier (1903-1914). Belo Horizonte: Editora UFMG, 2005.

FAORO, R. Os donos do poder: formação do patronato político brasileiro. $5^{{ }^{\mathrm{a}}}$ ed. São Paulo, Globo Editora, 2012.

FARIA FILHO, L. M.; GIL, N.; ZICA, M. C. Moderno, modernidade e modernização: a educação nos projetos de Brasil - séculos XIX e XX. Vol. 1. Belo Horizonte: Mazza Edições, 2012.

FERES JR., J.; SÁ, M. E. N. Civilização. IN: Léxico da História dos conceitos políticos do Brasil. FERES JR., J. (org). Belo Horizonte: Editora UFMG, 2014.

GOMES, A. C. (org.). Escrita de si. Escrita da História. Rio de Janeiro: Editora FGV, 2004.

. Minas e os fundamentos do Brasil moderno. Belo Horizonte, Editora UFMG, 2005.

GONÇALVES, I. A. A Formação do sujeito trabalhador na República: o ensino técnico profissional e a criança desvalida da fortuna. In: VI Congresso Brasileiro de História da Educação, Vitória, 2011, p. 45-60.

. Educação, Trabalho e República: o processo de escolarização das atividades manuais nos anos iniciais da República brasileira. In: SOUZA JR., H. P.; LAUDARES, J. B. (org.). Diálogos conceituais sobre trabalho e educação. Belo Horizonte: Editora PUCMINAS, 2011, p. 166-182.

. Progresso, trabalho e educação profissional em Minas Gerais. Belo Horizonte, Mazza Edições, 2012.

GONÇALVES, I. A.; NOGUEIRA, V. L. Educação e escolarização em Minas Gerais: o Legislativo e o Executivo como produtores da representação dos 
trabalhadores. In: GONÇALVES, I. A. (org.) Progresso, trabalho e educação profissional em Minas Gerais. Belo Horizonte, Mazza Edições, 2012, p. 41-60.

. Educação e escolarização em Minas Gerais: o legislativo e o executivo como produtores da representação dos trabalhadores. Saeculum, v. 22, p. 85-101, 2010.

GOODWIN JR., J. W. Cidades de papel: imprensa, progresso e tradição. Diamantina e Juiz de Fora, MG (1884-1914). Belo Horizonte: Fino Traço, 2015.

HOBSBAWM, E. J. A Era dos Impérios 1875-1914. São Paulo, Paz e Terra, 2011.

INÁCIO, M. S.; FARIA FILHO, L. M.; ROSA, W. M.; SALES, Z. E. S. Escola, política e cultura. Belo Horizonte: Argumentum, 2006.

JAPIASSÚ, H.; MARCONDES, D. Dicionário básico de Filosofia. $3^{\mathrm{a}}$ ed. Rio de Janeiro: Jorge Zahar, 1996.

KOSELLECK, R. Futuro passado. Contribuição à semântica dos tempos históricos. Rio de Janeiro: Contraponto, 2006.

KOWARICK, L. Trabalho e vadiagem: a origem do trabalho livre no Brasil. São Paulo: Brasiliense, 1987.

LAGES, R. C. L. As vitrines da civilização: referências estrangeiras na instrução pública em Minas Gerais no século XIX. Tese (Doutorado) - Universidade Federal de Minas Gerais, Belo Horizonte, 2013.

. Sobre educação moderna no século XIX: Minas Gerais/Brasil. In: VALLE, I. R.; HAMDAN, J. C.; DAROS, M. D. (org.). Moderno, modernidade, modernização: a educação nos projetos de Brasil - séculos XIX e XX. Vol. 2. Belo Horizonte: Mazza, 2014.

LIMA, B. B. P.; GOODWIN JR., J. W. A E.F. Leopoldina e o engrandecimento mineiro sob a perspectiva do senador Afonso Pena. XVI Seminário de Economia Mineira: repensando o Brasil. Diamantina, 2014.

MATTOS, I. R. Tempo Saquarema. São Paulo: HUCITEC, 1987.

MOTTA, R. P. S. (org.). Culturas políticas na história: novos estudos. Belo Horizonte, Fino Traço, 2009.

PÁDUA, P. G. O conceito de progresso nas mensagens dos presidentes do Estado de Minas Gerais (1891-1930). Dissertação (Mestrado) - Centro Federal de Educação Tecnológica de Minas Gerais, Belo Horizonte, 2012.

PERECIN, M. T. G. Os passos do saber: a Escola Agrícola Prática Luiz de Queiroz. São Paulo: EDUSP, 2004.

POCOCK, J. G. A. Linguagens do ideário político. São Paulo: EDUSP, 2013. 
SILVA, M. F. Indústria, trabalho e ensino profissional nos discursos de Roberto Cichrane Simonsen: os sentidos do americanismo. Dissertação (Mestrado) - Centro Federal de Educação Tecnológica de Minas Gerais, Belo Horizonte, 2015.

SWINLER, $A$. Culture in action: symbols and strategies. American Sociological Review, v. 51, 1986.

TILLY, C. Contentious repertoires in Great Britain, 1758-1834. Social Science History, v. 17, n. 2, 1978.

VALLE, I. R.; HAMDAN, J. C.; DAROS, M. D. (org.). Moderno, modernidade, modernização: a educação nos projetos de Brasil - séculos XIX e XX. Vol. 2. Belo Horizonte: Mazza, 2014.

VISCARDI, C. M. R. O teatro das oligarquias: uma revisão da "política do café com leite". Belo Horizonte: C/Arte Editora, 2012.

WIRTH, J. D. Minas Gerais na federação brasileira, 1889-1937: o fiel da balança. Rio de Janeiro: Paz e Terra, 1982.

\section{Fontes documentais}

Anais da Câmara dos Deputados do Estado de Minas Gerais. Congresso Mineiro. Anais da Câmara dos Deputados do Estado de Minas Gerais. Ouro Preto/Belo Horizonte: Imprensa Oficial do Estado de Minas Gerais, 1891-1906. Belo Horizonte: Arquivo Público Mineiro.

Anais do Senado Mineiro do Estado de Minas Gerais. Congresso Mineiro. Anais do Senado Mineiro do Estado de Minas Gerais. Ouro Preto/Belo Horizonte: Imprensa Oficial do Estado de Minas Gerais, 1891-1906. Belo Horizonte: Arquivo Público Mineiro.

Assembleia Legislativa Provincial. Anais da Assembleia Legislativa Provincial de Minas Gerais, 1874-1889. Ouro Preto: Typ. de J. F. de Paula Castro. 1864-1889. Belo Horizonte: Arquivo Público Mineiro. 